Análisis. Revista de investigación filosófica, Vol. 1, nº 1, 2014, pp. 223-230

\title{
Perspectivas Del NATURALISMO
}

\author{
Andrés Rubio Martínez
}

José Ignacio Galparsoro \& Alberto Cordero (Eds.), Reflections on Naturalism, Rotterdam/Boston/Taipei, Sense Publishers, 2013.

El naturalismo filosófico ocupa en el mundo anglosajón, ya desde hace tiempo, un lugar privilegiado desde el que contempla con desahogo los ímprobos y casi siempre estériles esfuerzos de otras corrientes filosóficas por sobrevivir en las procelosas aguas del ámbito académico por esos pagos. Esta acreditada relevancia todavía carece, sin embargo, del eco proporcional que le debería corresponder en nuestro entorno y, en consecuencia, libros como Reflections on Naturalism son - vaya esto por delante de cualquier otra consideración - absolutamente necesarios para cualquiera que pretenda estar mínimamente familiarizado con la actualidad del pensamiento contemporáneo.

Reflections on Naturalism viene a paliar una de las numerosas lagunas de nuestro panorama intelectual y lo hace de la mejor manera posible: a través de una fructífera colaboración en forma de obra colectiva entre investigadores de ambos lados del Océano Atlántico. Este volumen puede muy bien considerarse como uno de los "frutos colaterales" de la ejemplar trayectoria del Congreso Internacional de Ontología, así como del proyecto de investigación del Departamento de Filosofía de la Universidad del País Vasco "La naturalización de la filosofía: una reflexión metafilosófica en el contexto de la cultura contemporánea". Los editores, los profesores Alberto Cordero de la City University of New York y José Ignacio Galparsoro de la Universidad del País Vasco, han reunido en este volumen un interesante abanico de líneas abiertas de investigación que, de forma sucinta pero rigurosa, proporciona al lector una idea general bastante sólida acerca del naturalismo filosófico y algunas de sus derivaciones más relevantes en nuestros días.

La primera distinción que, con evidente ánimo pedagógico, se nos presenta es la distinción entre naturalismo ontológico y naturalismo epistemológico. El último se caracterizaría por el rechazo a todo apriorismo y 
por la exigencia de la aplicación de los controles de calidad científicos a todas las formas de conocimiento que aspiren a ser reconocidas como tales. Ninguna novedad respecto del cientismo al uso, rechazándose cualquier método, práctica o procedimiento ajeno a la praxis científica con el fin de obtener conocimiento. El primero, por su parte, vendría a refutar la existencia de entidades sobrenaturales. En principio respecto de este naturalismo ontológico, en buena medida a causa de su generalidad, no resultaría complicado encontrar una amplia adhesión. La simple expresión «entidades sobrenaturales» genera un rechazo inmediato y cualquier teoría que las excluya despierta nuestras simpatías metafísicas.

Sin embargo la cuestión es más peliaguda de lo que aparenta (siempre lo es). En efecto, considerar como relevantes única y exclusivamente las entidades naturales nos conduce directamente a la pregunta: ¿qué es natural? Y ésta a la temible ¿qué es la naturaleza? El naturalismo no parece vacilar ante semejantes cuestiones y nos remite sin más a lo que determinen las ciencias empíricas. Esta estrategia puede verse como la más sensata en un mundo como el nuestro en el que las ciencias ostentan el monopolio indiscutible de la generación de stocks de verdades, o bien como una elegante forma de lo que vulgarmente se conoce como "escurrir el bulto". Un "bulto" históricamente filosófico y que ésta - la filosofía - al menos en su forma naturalizada, renunciaría a seguir cargando sobre sus espaldas.

Llegados a este punto nos podemos preguntar cacaso es el naturalismo una corriente antifilosófica? ¿Una especie de caballo de Troya para acabar de una vez por todas con su ridícula fatuidad y entregar sus despojos como ofrenda al nuevo rey? A pesar de que algunos o muchos puedan considerar que la pretensión de naturalizar la filosofía no es más que una manera de desvirtuarla, de convertirla en disciplina ancilar, de desfilosofarla, en el volumen que nos ocupa se defiende con vehemencia la posición contraria, esto es, la de que el proyecto de naturalización de la filosofía, lejos de suponer su jaque mate, vendría a ser la postrera tabla de salvación que le devolvería parte del lustre perdido dotándola de una nueva interpretación omniabarcante que le posibilita llevar a cabo un metadiscurso acerca de todo. Como en los viejos tiempos.

Este nuevo rol supone, como apunta el profesor Galparsoro en su artículo, no sólo su rehabilitación y readmisión en el selecto club de la "ciencia" — sensu lato claro está- con una misión por fin clara y dejando de estar siempre en medio sin hacer nada salvo ser un estorbo. También supone la 
continuidad con una tradición de desvelamiento de una "ontología intuitiva" o "natural" llevada a cabo por filósofos de la talla de Aristóteles, Kant o Descartes y, al mismo tiempo, el compromiso con un pensamiento postdarwinista que se identificaría con el Nietzsche suspicaz de la genealogía, auténtico precursor del proyecto naturalista con su afán de retrotraer los principales conceptos de la filosofía y de la cultura en general a su origen natural, demasiado natural y traducirlos en términos psicobiológicos.

El naturalismo en este sentido no sería ni más ni menos que otra vuelta de tuerca en la historia de la reflexión filosófica que, con el tiempo, terminará siendo juzgada tan necesaria como las anteriores. Sólo que esta vez, la reflexión «metafilosófica» a la que nos invita el profesor Galparsoro, vendría a acabar con la pretensión de unicidad de la metafísica al considerarla un producto tan natural como cualquier otra representación cultural. Con ello la crítica a la crítica filosófica desembocaría necesariamente en una actitud teorética no natural, contraintuitiva o "artificiosa" respecto de lo que unos denominaron «koiné aisthesis», otros «gesunder Menschenverstand» y otros, simplemente, «bon sens». Nada demasiado alejado de lo que la filosofía siempre fue también.

El profesor Quintanilla, por su parte, trata de refutar en su artículo los a su juicio argumentos clásicos más importantes contra el naturalismo. Estos argumentos —esbozados por Edmund Husserl, pero de clara inspiración kantiana- giran en torno a una idea: la de la radical especificidad («trascendentalidad» en palabras de Kant) de la mente humana, tanto de su naturaleza, como de las leyes que la rigen, así como de su propia actividad conformadora de la realidad. Especificidad que desaconsejaría cabalmente tratarla como un objeto más de investigación a riesgo de caer en un reduccionismo al que estaría condenado todo proyecto monista-materialistanaturalista.

$\mathrm{El}$ autor defiende que tales objeciones conducen o bien a un misticismo propio de teorías que defienden realidades sobrenaturales tales como, en este caso, la mente humana; o bien a un dualismo que, a la postre, genera más problemas de los que solventa. Respecto a las acusaciones de reduccionismo, el autor sostiene la pertinencia de lo que se denomina como "naturalismo metodológico no reduccionista" para superarlas. Esta forma de naturalismo, haciendo uso del concepto de "supervenience" (una suerte de subrogación o dependencia por la que A podría darse sin B, pero no al revés, siendo A el cuerpo y B la mente), dividiría los entes en "supervinientes" y "supervenidos", pero unos y otros dentro del mismo (y único) orden ontológico. 
Dejando al margen el absurdo, tantas veces cometido en filosofía, de tratar de explicar asuntos complejos con conceptos todavía más complejos (hasta el punto de que su traducción a otro idioma se parece más a una tirada de dados que a otra cosa), la distinción mencionada nos recuerda irónicamente a la aristotélica entre sustancia y accidentes o a la cartesiana entre cualidades secundarias y primarias.

El profesor Prinz en su artículo «Measuring Morality» propone una interesante equivalencia entre argumentos (filosóficos) y experimentos a la par que aboga por una «filosofía experimental» basada fundamentalmente en los resultados de la cada día más influyente neurofilosofía. Su paráfrasis kantiana «sin ciencia la filosofía es ciega; y sin filosofía la ciencia está vacía» viene a resumir esta querencia por lo empírico, aunque a nuestros oídos suena mejor el retruécano con los términos invertidos.

A continuación el autor ilustra con numerosos ejemplos hasta qué punto pueden rastrearse, detectarse y evaluarse las emociones en el ámbito de investigación de la moral como hilo conductor más seguro para «medir la moral». Este neo-emotivismo — denominado «constitution theory» por el autor- equipararía de facto juicios morales con emociones, ofreciéndonos así una interesante explicación no sólo de los juicios morales, sino también de los juicios estéticos. En conclusión no habría hechos morales objetivos, sino juicios morales derivados de emociones socialmente inculcadas o prefiguradas. Las fronteras entre el prescriptivismo y el descriptivismo moral desaparecerían en consecuencia y la educación moral se basaría en un condicionamiento operante de las emociones a lo Skinner, en refuerzos o disuasiones fijadas por intereses sociales o grupales y ya no en supuestos valores objetivos o universales que en el fondo no serían — como ya advirtiera Nietzsche- más que intereses concretos que se pretende hipostasiar.

$\mathrm{El}$ artículo del profesor Cordero, «Naturalism and Scientific Realism» nos ofrece una valiosa y muy instructiva recapitulación de las tormentosas relaciones, de las coincidencias y de las diferencias entre el realismo naturalista, el realismo científico y sus diversos oponentes y rivales teóricos. Desde los albores del realismo naturalista con el darwinismo, pasando por la crisis del realismo en el tránsito de la mecánica newtoniana a la cuántica, el colapso del programa del empirismo lógico de reducción de lo real a términos observables, el antirrealismo kuhneano, hasta llegar a las aportaciones epistemológicas más recientes y su abigarrada variedad, el profesor Cordero hace un exhaustivo recorrido por los diferentes problemas y desafíos que la historia de la 
investigación científica en su desbocado avance genera a los filósofos de la ciencia en torno a la naturaleza de sus descubrimientos. El hecho de que unas teorías científicas sucedan a otras in the long run parece abonar las tesis antirrealistas e incluso relativistas. La propia posición teórica del naturalismo que confirma que nuestras percepciones y capacidades son fruto de un proceso de selección natural azaroso y aleatorio en el tiempo, no parece ofrecer mayores esperanzas al respecto.

Sin embargo, el éxito adaptativo de la especie, la consistencia, capacidad predictiva y confirmación de los datos de las teorías exitosas avalan tanto el realismo científico como el naturalista. El mero hecho de que unas teorías triunfen y otras no, que unas sean sustituidas por otras que se revelan mejores, indica que hay una aproximación —tal vez asintótica, pero aproximación al fin y al cabo- a la verdad y dado que, según autores como Dudley Shapere, no hay diferencia entre epistemología y metafísica en términos científicos, a la realidad. El círculo vicioso de la confirmación por el éxito y el éxito por la confirmación se convierte en la ecléctica propuesta que el profesor Cordero hace tras su análisis de las diversas posiciones, en un círculo virtuoso. El compromiso al que llega el realismo naturalista no promete justificaciones absolutas ni lo pretende. Demandar mayores garantías teóricas sería o demasiado metafísico, o demasiado no-realista en toda la extensión de la palabra.

El profesor Steven French analiza en su artículo las difíciles relaciones entre ciencia, metafísica y apuesta por una actitud conciliadora entre ambas. Si desde Carnap se ha considerado a la metafísica como una especie de gobbledygook, de jerga sin sentido, French menciona autores que defienden la pertinencia de su aportación en el ámbito de la filosofía de la ciencia y se posiciona con ellos atribuyendo un rol a la metafísica. Si el discurso sobre lo que es lo asume la ciencia en general y la física en particular, a la metafísica sólo le queda el discurso sobre lo que está más allá de lo observable, de lo empírico y, en consecuencia, sus divagaciones carecen de valor empírico y de interés para la ciencia. No hay mucho más que discutir, al menos desde un bando. Pero si, como defienden ciertas formas de realismo científico no precisamente minoritarias, se acepta la validez de afirmaciones sobre entidades inobservables dentro de una teoría empíricamente exitosa, parece que el "adiós a la metafísica» de van Fraassen (entre otros muchos), se convierte en un "cálido" recibimiento.

Ese retorno supondría, según el profesor French, la necesaria asunción de una actitud de humildad y modestia epistemológica, pues abrir de nuevo las 
puertas a la metafísica supondría dejar atrás la actitud de prepotencia con que se la expulsó de la casa de la ciencia. Léase "metafísica" en estos términos como sinónimo de "ignorancia" en el peor de los casos, o en el mejor como sinónimo de mortadela cuando no hay jamón.

Para reducir este impacto, para suturar el abismo que se podría abrir entre metafísica y epistemología, el autor propone embridar la metafísica con lo que denomina «Cassirer's Condition», esto es, restringir las condiciones de los objetos de la experiencia a las condiciones de accesibilidad. Y dado que todo a lo que tenemos acceso es estructura — según el realismo estructural- sería aconsejable adoptar ese punto de vista metafísico, contemplar la realidad como una estructura - siempre en construcción, siempre en busca de piezas que la formen- y evitar así los trompe l'oeil de la metafísica de la sustancia, objetual, cotidiana y, por ende, sus desajustes con las teorías físicas actuales.

El profesor Sergio F. Martínez, en su artículo «The Scientific Undercurrents of Philosophical Naturalism», lleva a cabo un interesante recorrido por la historia de la filosofía de la ciencia en estos dos siglos. Después de situar al «scaffold naturalism» o andamiaje del naturalismo a nivel ontológico como alternativa realista al no-realismo del empirismo lógico y al hiperrealismo metafísico al uso, y a nivel epistemológico como alternativa al psicologismo y al apriorismo, se remonta al padre putativo de la criatura Charles Darwin- y analiza su tesis de la continuidad, de cuya aceptación o rechazo depende el alcance de las explicaciones naturalistas y la necesidad de una naturalización de la epistemología. La "contaminación" naturalista (biologicista) de las ciencias, sociales o empíricas, ha tenido una legión de detractores desde el mismísimo Alfred Russel Wallace hasta los defensores a ultranza de las hard sciences; no obstante lo cual la extensión de modelos explicativos evolucionistas ha resultado imparable, siendo decisiva en el nacimiento de las ciencias cognitivas.

El que todas las representaciones culturales (esto es, todas las representaciones) estén empíricamente basadas en procesos neurológicos determinados por la historia evolutiva de la especie, es una explicación sin embargo tan sugerente como peligrosa. Peligrosa porque puede fácilmente ser tachada de pretenciosa, esto es, de reduccionista o incluso de relativista. El profesor Martínez aduce que el historicismo de Kuhn o la inconmensurabilidad de Feyerabend pueden resultar valiosas herramientas, a pesar de los esfuerzos del normativismo y el fundamentalismo metodológico por desacreditarlas, siempre y cuando no tengamos un concepto monolítico de racionalidad, 
estemos abiertos a la pluralidad de sus manifestaciones ("estilos" en palabras del autor), y no hagamos oídos sordos a los cambios, en ocasiones dramáticos, que son tan difíciles de percibir cuando todo cambia y sólo nos preocupa la acumulación y su propaganda en forma de progreso.

El profesor Ursúa aborda en su artículo uno de los problemas más fascinantes (si no el que más) de nuestros días: el problema del llamado "buman enhancement", la posibilidad de la mejora humana gracias a las tecnologías convergentes. En principio el naturalismo filosófico, al concebir a los seres humanos como seres biológicos sujetos a procesos mecánicos, físicos y evolutivos, refutaría el "argumento naturalista" que defiende que los seres humanos somos psicológicamente lo que la evolución ha hecho de nosotros naturalmente y así es como debe ser (y seguir siendo). Una concepción romántica de la sacralidad e inviolabilidad de la naturaleza choca sin embargo directamente con el devenir de facto de las capacidades y posibilidades humanas, siendo estas últimas, así como el deseo de la mejora técnica de las mismas que las acompaña, tan natural y "sagrado" como cualquier otro factor dado o heredado.

Ahora bien, esta esperanza de mejorar la condición humana, ya sea a través de terapias génicas, quirúrgicas (el "neuro-enhancement" a través de implantes, v. gr.) o farmacológicas, conviene el profesor Ursúa en que ha de ser regulado de alguna manera a riesgo, en caso contrario, de caer en el tecnofuturismo desbocado del posthumanismo. Las bondades de los avances técnicos son tan constatables como los peligros de la "barra libre" en sus aplicaciones. Entre concebir a la especie humana como una "pieza de museo" y describirla como una especie a superar en cuanto la tecnología nos lo permita, debe haber un punto medio.

El problema para el naturalismo filosófico es su complicada relación con el normativismo en general. La necesidad de una especie de "auditoría ética" de la que nos habla el autor, con el fin de preservar determinada esencia o de evitar que se sobrepasen ciertos límites "sagrados", no vemos cómo se puede llevar a cabo desde una filosofía que niega todo esencialismo y cualquier asomo de trascendencia. A no ser que volvamos de nuevo a darle vueltas al famoso "círculo virtuoso"...

En el último artículo del volumen que nos ocupa el profesor Julián Pacho aborda en su artículo "Naturalism and the Naturalization of Philosophy" la recurrente cuestión de la naturaleza y el rol de la filosofía, esta vez dentro del escenario y las coordenadas marcadas por el proyecto 
naturalista. ¿Se puede seguir filosofando después de la naturalización del conocimiento? ¿O sólo hay espacio para la ciencia?

Este tipo de reflexiones metafilosóficas, si bien siempre han estado presentes, se han acentuado ante el desafío que supone el "giro naturalista" para la disciplina. El autor analiza el proyecto de naturalización de la epistemología quineano y suscribe su afirmación de que "no hay exilio cósmico alguno para la filosofía". La pregunta que inmediatamente nos asalta, al menos a los interesados, es si hay exilio siquiera terrestre o, como afirma P. T. Sagal, el naturalismo supone en definitiva el harakiri de la filosofía.

De entrada la existencia de objetos filosóficos privilegiados o exclusivos es rechazada. También la posibilidad de fijar objetos eminentemente filosóficos a priori debido a su aparente indecibilidad, si bien el autor se adhiere a la tesis russelliana según la cual la ciencia se ocupa de lo que sabemos y la filosofía de lo que no sabemos (sólo que esto último sería absurdo determinarlo a priori). El argumento de "clausura cognitiva", que invoca los límites naturales de nuestra capacidad cognitiva, combinado con el llamado "efecto Hydra", según el cual la resolución de problemas y enigmas científicos no sólo no supone la disminución de los problemas no solucionados sino paradójicamente su aumento, parece garantizar para el autor la sostenibilidad de la filosofía, si bien recluida en la cara oscura del conocimiento lejos de los flashes del éxito epistémico.

Si ya no cabe hablar de objetos filosóficos par excellence en este contexto, el profesor Pacho se aventura a darnos tres condiciones necesarias, pero no suficientes per se, para delimitar el ámbito de los problemas filosóficos que, para poder seguir siendo considerados como tales según él, han de despertar un interés general, no han de generar un consenso definitivo y han de contar con una universalidad formal.

Reflections on Naturalism, en definitiva, es un volumen tremendamente útil para todos aquellos que pretendan familiarizarse o ponerse al día en una corriente tan influyente y desafiante desde el punto de vista teórico como el naturalismo filosófico, y pensar así en nuestro tiempo y no pensar sólo "sub specie aeterni". Máxime cuando es el propio naturalismo el que afirma que no hay tal cosa y, en consecuencia, sus aportaciones merecen todo menos la indiferencia filosófica. 